\title{
Clinical orofacial and myofunctional manifestations in an adolescent with Noonan Syndrome: a case report
}

\author{
Geciane Xavier Torres ${ }^{1}$ \\ https://orcid.org/0000-0002-2686-5374 \\ Emerson de Santana Santos ${ }^{2}$ \\ https://orcid.org/0000-0002-9175-2210 \\ Carla Patrícia Hernandez Alves Ribeiro César ${ }^{3}$ \\ https://orcid.org/0000-0002-9439-9352 \\ Roxane de Alencar Irineu ${ }^{3}$ \\ https://orcid.org/0000-0002-0614-4772 \\ Isabel Ribeiro Rocha Dias ${ }^{3}$ \\ https://orcid.org/0000-0002-8910-0627 \\ Alice Fontes Ramos ${ }^{4}$ \\ https://orcid.org/0000-0002-4807-352X
}

Universidade Federal de Sergipe - UFS, Lagarto, Sergipe, Brasil.

2 Universidade Federal de Sergipe - UFS, Departamento de Medicina, Lagarto, Sergipe, Brasil.

${ }^{3}$ Universidade Federal de Sergipe - UFS Departamento de Fonoaudiologia, Lagarto, Sergipe, Brasil.

Universidade Federal de Sergipe - UFS, Atenção Hospitalar à Saúde, Lagarto, Sergipe, Brasil.

Conflict of interests: Nonexistent

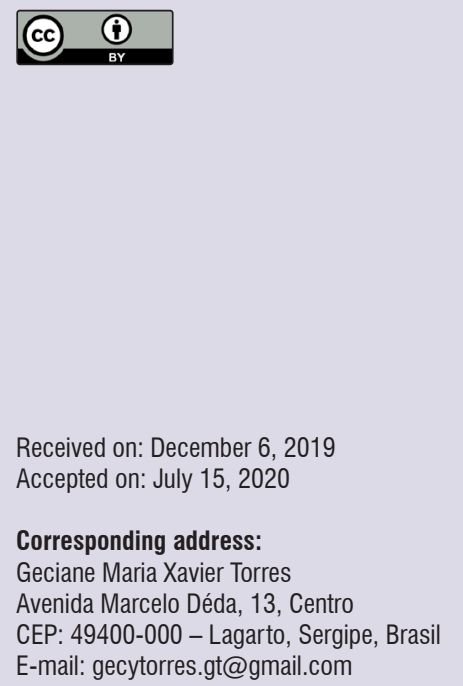

\section{ABSTRACT}

Noonan syndrome is an autosomal dominant genetic disease with different manifestations, including Speech, Language and Hearing Sciences ones. The authors describe the orofacial and myofunctional manifestations of an adolescent diagnosed with Noonan syndrome, by consulting the Speech, Language and Hearing Sciences record of a 17-year-old male patient, who underwent screening and speech therapy evaluation with a confirmed genetic diagnosis of Noonan syndrome. The results were qualitatively analyzed. The patient had a long facial type, with a disproportion between the lower and middle thirds of the face, ogival palate, and Mallampati class IV. A deficit in mobility and sensitivity of phonoarticulatory organs was also identified, absence of pathological oral and gag reflexes, decreased lip tone and tongue tension, increased speed chewing and inefficient grinding, functional swallowing for assessed consistencies, mild verbal and nonverbal apraxia, and moderate dysarthria. The results confirmed the presence of alterations in the speech-language organs, proving the relevance of the Speech, Language and Hearing Sciences evaluation in Noonan Syndrome, to allow adequate follow-up and treatment.

Keywords: Noonan Syndrome; Speech, Language and Hearing Sciences; Evaluation 


\section{INTRODUCTION}

Noonan syndrome (NS) was first described in 1963 by pediatric cardiologist Jacqueline Noonan ${ }^{1}$. Among the genetic syndromes, it is part of those with autosomal dominant inheritance, being a common monogenic disease within the RASopathies, with considerable genetic heterogeneity².

The term RASopathies is used to represent disorders caused by abnormalities in the RAS/MAPK ${ }^{3}$ signaling pathway. RAS are proteins that change their state between ON and OFF during signal transduction. When activated, they trigger a series of phosphorylations that result in the activation of MAPK (Mitogen-Activated Protein Kinase $)^{4}$. The MAPK pathway is associated with cell proliferation and growth ${ }^{5}$. Studies show that most of the genes that demonstrate to be mutated in NS cause unregulated signaling of the RAS/MAPK ${ }^{3,6}$ pathway and that the characteristics found in NS are due to the involvement of this signaling pathway?

The NS presents quite varied clinical characteristics. Among the systemic changes, we can highlight short stature, facial dysmorphism that varies with age, skeletal and ectodermal changes, pulmonary stenosis, lymphatic dysplasia, cognitive deficit, coagulation changes, cryptorchidism in male subjects and cardiac changes ${ }^{8}$.

The facial features of those with the syndrome are difficult to assess, as they may change throughout development. However, some features may be considered typical, such as a high forehead, triangular face, ocular hypertelorism, eyelid ptosis, external downward palpebral fissure, epicanthic folds, low implantation and incomplete rotation of the auricular pavilion, with a thickening of the auricular helix, deep filtrum, ogival palate, and short or webbed neck. Adults with NS have more subtle facial features, with less prominent eyes, slightly elongated neck, high anterior hair implantation, and facial wrinkles, especially on the forehead?

The diagnosis of NS should be based on clinical findings. However, this task can be difficult mainly due to the great phenotypic variability, with some patients presenting discrete facial features and without cardiac malformation ${ }^{1}$.

In this syndrome, there is also the need for differential diagnosis with Turner's syndrome (TS - affects only female patients and is associated with gonadal dysgenesis), which is done through the karyotype. The karyotype differentiates the TS from the NS due to the presence of complete or partial monosomy of sex chromosomes in TS, while patients with NS have a normal karyotype ${ }^{9}$.

Among the intraoral manifestations, a retrospective study identified malocclusion (a transverse maxillary deficiency, crossbite, anterior open bite and class II malocclusion), dental anomalies (late eruption, agenesis and dystrophy, odontoma), and mandibular radiological injuries in $50 \%$ of the patients ${ }^{10}$.

A study recorded a six-year-old male child with facial dysmorphism with bilateral telecanthus, hypertelorism, ptosis and exophthalmia tendency, inverted triangular face, relatively large nose, bulky lips, usual posture of parted lips, anterior open bite, narrow and ogival palate, adapted swallowing, presence of polycaries due to prolonged nursing bottle use, and oral breathing without airway obstruction ${ }^{11}$.

There are reports in the literature of speech and language disorders in NS, with changes in oral and written language due to intellectual and/or auditory deficit, motor impairment, in articulation, in phonological memory ${ }^{12,13}$, and with slow oral transit time $(\mathrm{OTT})^{14}$. However, in orofacial motricity, clinical reports of patients with NS are scarce.

Thus, this study aimed to describe the orofacial myofunctional manifestations of an adolescent diagnosed with Noonan syndrome.

\section{CASE REPORT}

To begin the investigation, family members and the patient freely consented to participate in the research and allowed the dissemination of images, after signing the free and informed consent form and later approval of the research by the Ethics Committee of the Federal University of Sergipe, SE, Brazil, under number 3.377.647, CAEE approval 13370819.2.0000.5546.

To deepen studies on orofacial myofunctional manifestations in NS, this exploratory, descriptive, retrospective and qualitative case report was performed through the analysis of speech therapy records in the medical records of a 17-year-old patient, male, diagnosed, at three months of age, with the aforementioned syndrome (Figure 1). The patient was seen at a Speech, Language and Hearing Sciences School Clinic at a university in northeastern Brazil. 


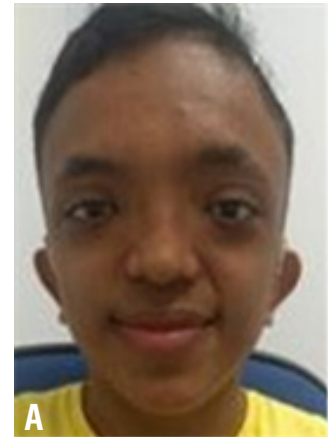

Figure 1. A - Front Profile

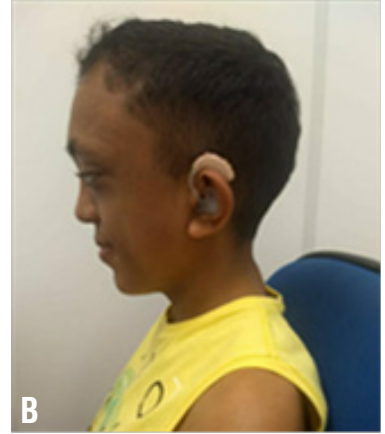

B - Lateral Profile
Information related to anamnesis (with the person responsible and the patient himself) and speech therapy evaluation (with the aid of the MBGR ${ }^{15}$ protocols for the assessment of orofacial motricity, verbal and non-verbal apraxia $^{16}$ and assessment of dysarthria ${ }^{17}$ ) were collected in an appropriate room of the School Clinic of a higher education institution on a previously scheduled day and time, as described in the results.

\section{RESULTS}

\section{Relevant anamnesis data}

The teenager is the son of consanguineous parents and his diagnosis was confirmed after a karyotype performance due to congenital malformations. The mother reported that the pregnancy was desired, that she had prenatal care, with vaginal delivery, cephalic presentation, and preterm (33 weeks). She remained in the maternity hospital for one month due to neonatal complications, such as the presence of jaundice and prematurity.

In 2018, the patient was evaluated by the Medical Genetics outpatient clinic at the university, and the physical examination showed an atypical gait, greater length of the limbs in relation to height, a macrocephalic skull with the prominence of the frontal region, low implantation of the ears, eyes with downward eyelids, exophthalmia, short neck, atypical and symmetrical chest. The neurological examination revealed the presence of bilateral vertical nystagmus and dysarthria.

After genetic evaluation and conduct, the patient was referred to the Speech, Language and Hearing Sciences sector, and screening was carried out to collect the data regarding the patient's clinical history, followed by the description of the case and conduct.

Regarding motor aspects, according to the mother, the patient has difficulties while getting dressed, tying the shoes and buttoning clothes, in addition to mentioning that he was always short for his age.

Regarding respiratory aspects, the patient has chronic maxillary sinusitis. There is a maternal complaint that his sleep is agitated, fragmented, with snoring and drooling on the pillow. He makes use of the drug neuleptil ${ }^{\circledR}$, the brand name of periciazine, prescribed by a neurologist for continuous use. This medication is an antipsychotic used to control behavior and motor instability, as it produces as a side effect the induction of sleep without causing dependence.

According to the mother, her son is sociable and is well adapted to regular public schools, attending the first year of high school. He has difficulties in the learning process and is currently being accompanied by a speech therapist, a neurologist (due to complaints of headache and difficulties sleeping), and receives psychological treatment. The patient presents mixed hearing loss of moderate degree bilaterally and is fitted in both ears, being accompanied by the hearing rehabilitation services in his hometown.

After screening, the speech-language evaluation was performed, using protocols ${ }^{15-17}$ and materials, such as Altmann's millimeter mirror, Vonder ${ }^{\circledR}$ metallic caliper, Sony Cyber-Shot digital camera (7.2 megapixels), model DSC P200, food (bread and water offered in a transparent glass), flashlight and wooden spatula, which revealed the results described below.

\section{Orofacial Motricity Evaluation}

In the analysis of the clinical examination, the postural characteristics of the head, neck, shoulders, and phonoarticulatory organs were investigated, both in the performance of stomatognathic functions and in a resting position. The patient presented an anterior and inclined head regarding the chest, a short neck, and an elevation of the right shoulder.

Regarding facial characteristics, there is slight facial asymmetry, triangular face, wide forehead, ocular hypertelorism, antimongolic fissure, and low ear implantation, with asymmetrical auricular helix thickening (greater than 40 degrees) between the ears, more accentuated in the left one.

In the extra and intraoral verification of the phonoarticulatory organs (PHOs), a long facial typology was observed, with disproportion between the lower and middle thirds of the face, usual position of the parted lips, ogival palate, Mallampati class IV, tongue with increased height, absent gag and pathological reflexes, and spontaneous swallowing of saliva. Furthermore, 
were observed deficits in the mobility of PHOs with difficulties to protrude, lateralize and snap lips, in protruding and vibrating the tongue, a decreased tonus of lips and tongue tension, and a decreased sensitivity of the PHOs. Regarding occlusion, Class I was found according to the Angle classification, with no signs and symptoms related to the temporomandibular disorder. Besides, the patient had poor dental preservation and canker sores on the gums.

As for stomatognathic functions, the adolescent presented medium/upper respiratory type, oronasal mode with a similar expiratory nasal flow between the nostrils. The chewing pattern was preferably unilateral, with lip sealing, increased speed, and inefficient crushing.

For the functional evaluation of the swallowing dynamics, water, bread, and, in a second moment, couscous was used, at the mother's request, since it was the food that, according to her, the patient choked while eating.

The food was handled by the patient himself, observing good performance, adequate intake of the bolus, and lip sealing. The supply of solid food (couscous) was in large volume, presenting slow oral transit times (OTT). Were observed: the absence of extraoral escape, sufficient laryngeal elevation, cervical auscultation without alteration before, during, and after the offer, absence of signs of laryngeal penetration/ aspiration, considering the functional swallowing for the evaluated consistencies.

The patient is short and, for this reason, he was referred to the endocrinologist and, due to the observation of his apparently lean body mass, he was referred to the Nutrition clinic.

\section{Assessment of verbal and non-verbal apraxia}

The tests for the assessment of non-verbal praxis consisted of twenty isolated movements (showing teeth, showing a smile, protruding the tongue, blowing, raising the tongue, biting the lower lip, clearing the throat, lowering the tongue, making a beak, coughing, puffing out the cheeks, sending a kiss, lateralizing the jaw, passing the tongue over the lips and clicking the tongue), sequentially (protruding and retracting the tongue, lateralizing, elevating and lowering the tongue, alternating beak and smile, lateralizing and elevating the tongue), performed by the patient after a verbal command. Some movements were demonstrated by the evaluator to facilitate performance through visual cues. The teenager obtained ninety points, being classified as mild non-verbal apraxic.

The verbal tasks applied were repetition of words and phrases, emission of automatisms, spontaneous speech, and reading aloud. In the task of repeating words and sentences, the stimuli were read so that the adolescent could repeat them. In spontaneous speech, he was asked to describe a picture of a specific thematic card, the picture being described in just two sentences, showing reduced expressive language. In automation, it was requested to count numbers from zero to twentyone and the months of the year, and it was found that the patient did not know how to say every month in the sequence. When reading words and phrases aloud, he presented difficulties while reading some sentences. He displayed articulatory groping when he started speaking, phoneme substitution errors, inconsistent phoneme changes in speech, vowel errors, increased number of errors in larger units of speech, impaired voluntary oral movements, as well as difficulties in imitating words and phrases, evidencing mild verbal apraxia.

\section{Assessment of dysarthria}

For the evaluation of dysarthria, a translated and adapted protocol, suitable to the phonetic and linguistic characteristics of the Portuguese language spoken in Brazil ${ }^{17}$, was used. The evaluation protocol included the analysis of the following speech components: breathing, phonation, resonance, articulation, and prosody.

When applied, it was observed that the participant presented, regarding the variable maximum phonation time, an average of $6.3 \mathrm{~s}$ and $6.1 \mathrm{~s}$ respectively for the vowels /a/ and /i/, $3.5 \mathrm{~s}$ for $/ \mathrm{s} /$ and $4.3 \mathrm{~s}$ for $/ \mathrm{z} /$. There were 24 respiratory cycles per minute and an $\mathrm{s} / \mathrm{z}$ ratio of $0.8 \mathrm{~s}$. For the analysis of vocal parameters, a perceptualauditory vocal analysis was performed, conferring vocal quality with the presence of hoarseness and harshness, as well as a sudden vocal attack. As for the resonance variable, the dysarthria evaluation protocol has only three possibilities for classification: normal, hyper, and hyponasal, but the participant of this research presented laryngopharyngeal resonance and is thus described as an observation in his medical record.

The participant presented significant changes in articulation and prosody with difficulties to perform lip, tongue, and jaw movements, displaying reduced motion, the amplitude of the articulators, and a slight to moderate alteration in speech intelligibility, worsening 
the result for diadochokinesis and in larger units of speech. In evaluating the prosody, the participant presented inappropriate pauses, inadequate marking of stressed syllables, and sentence termination. The score was sufficient to classify it, according to the protocol used, as moderate dysarthria.

\section{DISCUSSION}

Case studies are important as research modalities for understanding relevant clinical situations, especially in exploratory investigations. Although NS has been described since $1963^{1}$, there is scarce literature on orofacial motricity about its clinical manifestations.

Among the clinical manifestations, the patient has short stature, a common feature in NS and, for that aspect, there is the possibility of treatment with growth hormone (hrGH), according to Malaquias et al. ${ }^{1}$ and, for this reason, the patient was referred to an endocrinologist.

Due to short stature, patients with this syndrome can be treated with growth hormone. According to the literature, there may be a correlation between hormonal use for growth and brain tumors, in which apraxia may be evident, as described in a clinical case with NS and the presence of an oligoastrocytoma ${ }^{18}$, with the apraxia observed in this patient monitored in an interdisciplinary and longitudinal way.

Other clinical alterations were also verified and ratified by the literature, such as triangular face, external palpebral fissure diverted downward, low implantation of the auricular pavilion, with thickening of the auricular helix and short neck and high anterior hair implantation 7,11 , ocular hypertelorism and telecanthus ${ }^{7,11,19}$, nystagmus ${ }^{20}$, short stature ${ }^{18}$, and hearing loss ${ }^{21}$.

Studies have presented important data on hearing impairment found in patients with $\mathrm{NS}^{21-23}$. Sensorineural hearing impairment was found in $50 \%$ of the 40 ears assessed in patients affected with $\mathrm{NS}^{22}$. Another study evaluated external anomalies of the ear and hearing impairment in patients with NS, finding the presence of external anomalies of the ear in $77 \%$ of the sample and hearing impairment in $34 \%$ of the participants, $4 \%$ of whom presented mixed hearing loss ${ }^{23}$, the same type of loss described in this case study.

Regarding the stomatognathic functions, the patient presented changes in swallowing, breathing, chewing, and speech.

As for swallowing, we verified the OTT, which is defined as beginning by the anteroposterior propulsion of the tongue with food inside the oral cavity and ending when the bolus begins its course in the hypopharynx. This was shown to be slowed in the present clinical case. Researchers ${ }^{14}$, when reporting a series of cases with genetic alterations, also found changes in the OTT in liquids in a patient with NS, corroborating the evidence found. Researchers ${ }^{14}$, when reporting a series of cases with genetic alterations, also found changes of the OTT in liquids in a patient with NS, corroborating the evidence found. The authors ${ }^{14}$ found changes in the pharyngeal transit time in the NS patient of the study for the liquid and pasty consistencies. However, this was a limitation of the present study, considering that the evaluation was of the clinical myofunctional type, therefore, subjective, with no imaging exam for its confirmation. Such finding is justified by the patient's oromotor difficulties, that is, by the presence of apraxia, even if in a mild degree. Besides, Schmatz ${ }^{24}$, when presenting a protocol that aims to assess the risk for childhood dysphagia, described a case of a patient with NS who presented such a risk.

According to the literature ${ }^{25}$, genetic factors due to increased signaling of the RAS-MAPK pathway may give patients a thinner profile due to the impairment of body fat and musculature. Therefore, it is hypothesized that muscle strength may be compromised in the function of chewing, in which bite force is required for the food incision. Under these conditions, compensatory mechanisms may be used to perform this muscle activity. Another fact that can impair chewing is the possibility of severe polycaries in these patients ${ }^{26}$. However, this was not observed in the clinical case analyzed.

Another manifestation found in this case study was the altered breathing mode associated with the presence of Mallampati IV, which can be considered as risk factors for obstructive sleep apnea ${ }^{27}$. In a literature review paper ${ }^{28}$, the NS was presented as one of the several syndromes in which obstructive sleep apnea occurs. For this syndrome, it is due to facial deformity, maxillomandibular discrepancy, and the possibility of pharyngeal tonsil hypertrophy. Therefore, the patient was referred for an otorhinolaryngological evaluation, for the adequate procedures.

Dysarthria was reported in a clinical case ${ }^{29}$ of a 34-year-old Thai woman who was hypertensive, diabetic, dyslipidemic, and had NS, but the event occurred after a subcortical infarction of the right middle cerebral artery. The authors commented that strokes can occur in this syndrome due to vascular malformations ${ }^{29}$, justifying the monitoring of the patient 
with the neurologist. Regarding the possibilities of cardiovascular changes, as mentioned in the literature ${ }^{8}$, the patient was referred to a cardiologist.

It is important to consider that the hearing loss present in the patient may have influenced speech production. A study evaluated the production of vowels in speakers with different hearing loss levels by comparing them with normal-hearing speakers and found a reduced articulatory working space in the group with conductive and mixed hearing losses when compared with the control group, indicating less intelligible speech ${ }^{30}$.

The manifestations presented in this clinical case may, due to structural changes, limit the proper functioning of the stomatognathic system, thus revealing the importance of interdisciplinary evaluation and treatment for better performance of the orofacial and cervical complex.

\section{FINAL CONSIDERATIONS}

NS can present systemic changes relevant to the performance of stomatognathic functions. The structural and functional changes in the phonoarticulatory organs - mainly in mobility, impaired speech intelligibility, and presence of associated dysarthria and apraxia - present in the clinical case, ratified the relevance of orofacial myofunctional assessments in NS. Those, added to the learning difficulties and bilateral moderate mixed hearing loss, demonstrate the need for speech therapy intervention, to minimize the impact of these changes on the quality of life of patients affected by the syndrome.

Besides, NS needs an interdisciplinary follow-up due to its extreme phenotypic variability, ranging from craniofacial and cardiac changes, coagulation defects, ectodermal changes, and cognitive deficit. Therefore, several health professionals should be teamed up for the assessment and care of patients diagnosed with this syndrome.

\section{REFERENCES}

1. Malaquias AC, Ferreira LV, Souza SC, Arnhold IJP, Mendonça BB, Jorge AAL. Síndrome de Noonan: do fenótipo à terapêutica com hormônio de crescimento. Arq Bras Endocrinol Metab. [serial on the Internet]. 2008 May [cited 2019 Sept 03];52(5):[about 9 p.]. Available from: http://www.scielo.br/scielo.php?script $=$ sci_ arttext\&pid=S0004- 27302008000500012\&lng =en.
2. Moraes MB. Estudo clínico e molecular de pacientes com síndrome de Noonan e síndromes relacionadas à síndrome de Noonan pelo sequenciamento de nova geração [tese]. São Paulo (SP): Universidade de São Paulo; 2019.

3. Aoki $Y$, Niihori T, Inoue S, Matsubara Y. Recent advances in RASopathies. J hum. genet. 2016;61(1):33-9.

4. Simanshu DK, Nissley DV, Mccormick F. Ras proteins and their regulators in human disease. Cell. 2017;170(1):17-33.

5. Silva BV, Horta BAC, Alencastro RB de, Pinto AC. Proteínas quinases: características personalizadas e inibidores químicos. Qim. nova. 2009;32(2):453-62.

6. Rauen KA. As RASopatias. Annu. rev. genomics hum. genet. 2013;14:355-69.

7. El Bouchikhi I, Belhassan K, Moufid FZ, Houssaini MI, Bouguenouch L, Samri I et al. Noonan syndrome-causing genes: molecular update and an assessment of the mutation rate. J. pediatr. adolesc. med. 2016;3(4):133-42.

8. Tkachenko N. Síndrome de Noonan. Nascer crescer. 2016;25(suppl 1):7.

9. Tartaglia M, Martinelli S, Stella L, Bocchinfuso G, Flex E, Cordeddu $V$ et al. Diversity and functional consequences of germline and somatic PTPN11 mutations in human disease. Am. j. hum. genet. 2006;78(2):279-90.

10. Lutz JC, Nicot R, Schlund M, Schaefer E, Bornert F, Fioretti $\mathrm{F}$ et al. Dental and maxillofacial features of Noonan syndrome: case series of ten patients. J. craniomaxillofac. surg. 2020;48(3):242-50.

11. Mocanu RM, Zetu IN, Vulpoiu C, Bălan A. Orofacial findings in Noonan syndrome: a case report. Intern. j. med. dent. 2013;3(17):162-5.

12. Wilson M, Dyson A. Noonan syndrome: speech and language characteristics. J. commun. disord. 1982;15(5):347-52.

13. Pierpont El, Weismer SE, Roberts AE, Tworog-Dube E, Pierpont ME, Mendelsohn NJ et al. The language phenotype of children and adolescents with Noonan syndrome. J. speech lang. hear. res. 2010;53(4):917-32.

14. Sales AVMN, Cola PC, Santos RRD, Jorge AG, Berti LC, Giacheti CM et al. Quantitative analysis of oral and pharyngeal transit time in genetic syndromes. Audiol., Commun. res. [serial on the Internet]. 2015 Jun. [cited 2019 Sept 03];20(2):[about 5 p.]. Available from: http://www.scielo.br/ 
scielo.php?script $=$ sci_arttext $\&$ pid $=$ S2317$64312015000200011 \&$ Ing $=$ en.

15. Marchesan IQ, Berretin-Felix G, Genaro KF. MBGR: protocolo de avaliação em motricidade orofacial com escores. In: Tessitore A, Marchesan IQ, Justino $\mathrm{H}$, Berretin-Felix $\mathrm{G}$ (orgs). Práticas clínicas em motricidade orofacial. 2. ed. Pinhais: Melo; 2016. p. 97-116.

16. Martins FC, Ortiz KZ. Proposta de protocolo para avaliação da apraxia da fala. Fono atual. 2004;7(30):53-61.

17. Fracassi AS, Gatto AR, Weber S, Spadotto $A A$, Ribeiro PW, Schelp AO. Adaptação para a língua portuguesa e aplicação de protocolo de avaliação das disartrias de origem central em pacientes com doença de Parkinson. Rev. CEFAC. 2011;13(6):1056-65.

18. Jacquinet A, Bonnard A, Capri Y, Martin D, Sadzot $B$, Bianchi $E$ et al. Oligo-astrocytoma in LZTR1related Noonan syndrome. Eur. j. med. genet. 2020;63(1):103617.

19. Oliveira PHA, Souza BS, Pacheco EN, Menegazzo MS, Corrêa IS, Zen PRG et al. Síndromes genéticas associadas a defeitos cardíacos congênitos e alterações oftalmológicas - sistematização para o diagnóstico na prática clínica. Arq. bras. cardiol. [serial on the Internet]. 2018 Jan [cited $2020 \mathrm{Apr}$ 03];110(1):84-90. Available from: http://www. scielo.br/scielo.php?script $=$ sci_arttext $\&$ pid $=$ S0066-782X2018000100084\&lng=en. https://doi. org/10.5935/abc.20180013.

20. van Trier DC, van der Burgt I, Draaijer RW, Cruysberg JR, Noordam C, Draaisma JM. Ocular findings in Noonan syndrome: a retrospective cohort study of 105 patients. Eur. j. pediatr. 2018;177(8):1293-8.

21. Tokgoz-Yilmaz S, Turkyilmaz MD, Cengiz FB, Sjöstrand AP, Kose SK, Tekin M. Audiological findings in Noonan syndrome. Int. j. pediatr. otorhinolaryngol. 2016;89:50-4.

22. Qiu WW, Yin SS, Stucker FJ. Manifestações audiológicas da síndrome de Noonan. Otolaryngol. head neck surg. 1998;118(3):319-23.

23. van Trier DC, van Nierop J, Draaisma JM, van der Burgt I, Kunst $\mathrm{H}$, Croonen EA et al. External ear anomalies and hearing impairment in Noonan syndrome. Int $\mathrm{J}$ Pediatr Otorhinolaryngol. 2015;79(6):874-8.

24. Schmatz AP. Elaboração de instrumento para rastreio do risco de disfagia orofaríngea infantil [dissertação]. Marilia (SP): Universidade Paulista Júlio de Mesquita Filho; 2013.

25. Kanno FMS. Caracterização do estado nutricional de pacientes com síndrome de Noonan e síndromes Noonan-like [dissertação]. São Paulo (SP): Universidade de São Paulo; 2015.

26. Leache EB, Ontiveros DS, Edo MM. Análisis etiopatogénico de la caries en tres pacientes con Síndrome de Noonan. Med. oral. 2003;8(2):136-42.

27. Rodrigues MM, Dibbern RS, Goulart CWK. Nasal obstruction and high mallampati score as risk factors for obstructive sleep apnea. Braz. j. otorhinolaryngol. [serial on the Internet]. 2010 Oct. [cited 2019 Sept 04];76(5): [about 3 p.]. Available from: http://www.scielo.br/scielo.php?script $=$ sci arttext\&pid=S1808- 86942010000500010\&lng=en.

28. Zaffanello M, Antoniazzi F, Tenero L, Nosetti L, Piazza M, Piacentini G. Sleep- disordered breathing in paediatric setting: existing and upcoming of the genetic disorders. Ann. transl. med. 2018;6(17):343.

29. Eu-Ahsunthornwattana J, Trachoo O, Dejsuphong D, Tunteeratum A, Srichan K, Sura T. Noonan syndrome, metabolic syndrome and stroke-in-theyoung: coincidence, causal or contribution. J. Med. Assoc. Thai. 2010;93(9):1084-7.

30. Hung YC, Lee YJ, Tsai LC. Vowel production of mandarin-speaking hearing aid users with different types of hearing loss. PLoS One. 2017;12(6):1-16. 